\title{
Ocular findings in patients with novel A/H1N1 infection: an
}

\section{observational cross-sectional study [version 1; peer review: 1 approved with reservations, 1 not approved]}

\author{
Salil Mehta (i1, Conrad Rui Vas² \\ ${ }^{1}$ Ophthalmology, Lilavati Hospital and Research Centre, A-791, Bandra Reclamation, Bandra West, Mumbai, Maharashtra, 400050, \\ India \\ ${ }^{2}$ Critical Care Medicine, Lilavati Hospital and Research Centre, A-791, Bandra Reclamation, Bandra West, Mumbai, Maharashtra, \\ 400050, India
}

V1 First published: 24 May 2019, 8:738

https://doi.org/10.12688/f1000research.18927.1

Latest published: 24 May 2019, 8:738

https://doi.org/10.12688/f1000research.18927.1

\section{Abstract}

Background: The systemic findings of novel A (H1N1) influenza have been well documented but data on ocular lesions is scarce. We report the systemic and ophthalmoscopic findings of 14 patients with proven H1N1 infection.

Methods: An observational non-interventional retrospective study. During a period of nine years, 14 patients (six female and eight males), were referred for an ophthalmic evaluation. All patients underwent a detailed systemic and ocular evaluation.

Results: Three patients (21.4\%) showed ocular lesions in the form of a unilateral intraretinal hemorrhage. Of these, one patient $(7.1 \%)$ had a large disc hemorrhage and an area of retinal whitening, consistent with ischemia in the macular area.

Conclusions: Physicians dealing with H1N1 infection should be aware of these findings and may include an ocular evaluation as part of their protocol.

\section{Keywords}

H1N1, ocular, pandemic, infections

Open Peer Review
Approval Status ?
version 1
Medical Education and Research (PGIMER),
Chandigarh, India
2. Fehim Esen, Istanbul Medeniyet University
School of Medicine, Istanbul, Turkey
Any reports and responses or comments on the
article can be found at the end of the article.


Corresponding author: Salil Mehta (drsalilmehta@gmail.com)

Author roles: Mehta S: Conceptualization, Data Curation, Formal Analysis, Investigation, Methodology, Writing - Original Draft Preparation, Writing - Review \& Editing; Vas CR: Project Administration, Writing - Review \& Editing

Competing interests: No competing interests were disclosed.

Grant information: The author(s) declared that no grants were involved in supporting this work.

Copyright: $\odot 2019$ Mehta S and Vas CR. This is an open access article distributed under the terms of the Creative Commons Attribution License, which permits unrestricted use, distribution, and reproduction in any medium, provided the original work is properly cited.

How to cite this article: Mehta $S$ and Vas CR. Ocular findings in patients with novel A/H1N1 infection: an observational crosssectional study [version 1; peer review: 1 approved with reservations, 1 not approved] F1000Research 2019, 8:738

https://doi.org/10.12688/f1000research.18927.1

First published: 24 May 2019, 8:738 https://doi.org/10.12688/f1000research.18927.1 


\section{Introduction}

Novel A/H1N1 influenza (previously termed as swine flu) is a common infectious disease in India (12,942 infections causing 954 deaths in $2018^{1}$ ) and globally ${ }^{2}$. The respiratory system is primarily affected by infection and extensive data is available for the interaction of $\mathrm{A} / \mathrm{H} 1 \mathrm{~N} 1$ with the respiratory system ${ }^{3}$. Systemic viral infections (human immunodeficiency virus (HIV), cytomegalovirus, herpes simplex, herpes zoster, chikungunya and West Nile virus) are commonly associated with ocular lesions, usually posterior uveitis, due to their hematogenous dissemination. HIV infection, additionally, shows a classic microvasculopathy (cotton wool spots or hemorrhages) that reflect direct endothelial infection. However, reports of ocular lesions (infective or vasculopathic) in $\mathrm{A} / \mathrm{H} 1 \mathrm{~N} 1$ infections are limited. Published reports ${ }^{5,6}$ present single patient findings but aggregate data from multiple cases are not available. This study was intended to ascertain the presence and types of ocular lesions in novel $\mathrm{A} / \mathrm{H} 1 \mathrm{~N} 1$ infections and reports findings from 14 patients.

\section{Methods}

Approval for retrospective data collection and publication was granted by the institutional ethics committee of Lilavati Hospital and Research Center (approval dated 09/04/2019) The requirement for individual consent was waived.

A retrospective cross-sectional observational study. We evaluated the records of all patients examined in the medical intensive care unit of a medium-sized (320 beds) tertiary referral hospital (Lilavati Hospital and Research Center) from 2015 until 2018. This was done over a month (February 2019). As part of a standard hospital protocol, patients with pyrexia of unknown origin (PUO), at the specific discretion of the admitting physician, undergo a bedside dilated fundus evaluation. A total of 14 patients (six female and eight males, ages ranging from 36-78 years, mean 54.07 years) met the criteria for inclusion (positive tests for novel $\mathrm{A} / \mathrm{H} 1 \mathrm{~N} 1$ infection and having been ophthalmologically evaluated) and their records were analyzed. Of these, $13(92.8 \%)$ were admitted in the intensive care/isolation unit and one $(7.1 \%)$ chose to be managed on an outpatient basis.

All patients underwent a detailed evaluation on admission, including a complete blood count (hemoglobin estimation, total and differential white cell counts and platelet counts), blood sugar tests (random on admission, fasting if deemed necessary), liver (serum glutamic-oxaloacetic transaminase (SGOT)/serum glutamic pyruvic transaminase (SGPT)) and renal function tests (serum creatinine and blood urine nitrogen, if needed), urine analysis (routine and microscopy), procalcitonin (PCT) estimation and prothrombin time (PT)/partial thromboplastin time (PTT) studies. Radiological evaluation included chest $\mathrm{X}$-rays and a follow-up chest computed tomogram (CT), at the intensivist's discretion. An infectious disease evaluation included peripheral blood smears for malarial parasites, rapid NS1 antigen detection for dengue infection and serology for chikungunya (serum $\mathrm{IG} / \mathrm{IgM}$ ) and/or hantavirus infection (serum IgG/IgM estimation). A nasopharyngeal swab was sent for reverse transcriptasepolymerase chain reaction (RT-PCR) for H1N1 infection. Patients who were permitted to receive domiciliary care underwent a slitlamp evaluation, dilated fundus evaluation and intraocular pressure evaluation in the outpatient department.

Data were entered into a spreadsheet (Excel for Mac, Microsoft Corp, WA, version 16.16.9) and analyzed with the inbuilt statistical functions.

\section{Results}

The presenting complaints of the 14 patients were persistent fever, cough, sore throat and progressively worsening dyspnea for five to seven days prior to admission ${ }^{7}$. Demographic information and clinical presentations can be found in Table 1. Significant pre-existing diseases included type 2 diabetes mellitus in three patients $(21.4 \%$, ages ranging from $74-78$ years with a mean of 75.66 years - cases 3, 5 and 14), with additional chronic liver disease in one of these patients $(7.4 \%$, 74-year-old female case 5).

All of the patients were febrile, tachypneic and tachycardic. Chest imaging (x-rays and chest scans) revealed extensive bilateral fluffy infiltrates in five patients that were admitted with acute respiratory distress syndrome $(35.7 \%$ - cases $1,2,8,9$ and 11). Other chest imaging findings included unilateral/bilateral patchy infiltrates or consolidation in two patients $(21.4 \%$ - cases 4 and 6). Five patients (35.7\% - cases 3, 5 and 12-14) had normal chest findings on chest radiology.

The findings of hematological tests including complete blood count (hemoglobin estimation, total and differential white cell counts) and platelet counts were normal. A bleeding diathesis was ruled out by normal PT/PTT values (11 to 13.5 seconds), in nine (64.2\%) of these patients. Liver function tests (SGOT /SGPT) revealed marked hepatic dysfunction in one patient (case $6-7.1 \%$ ) and were normal (SGOT 5-40 U/L, SGPT 7-56 U/L) or borderline elevated in the rest. Renal function tests (serum creatinine and blood urea nitrogen) were normal in all cases (creatinine $<1.2 \mathrm{mg} \%$, blood urea nitrogen 5-20 mg\%) except three (cases 3,5 and $13-21.4 \%$ ). Random blood sugars on admission were grossly abnormal in one patient (case $9-317 \mathrm{mg} \%$ ) and were normal $(<160 \mathrm{mg} \%)$ in the rest. Bacterial infection was ruled out, where available, by normal PCT values $(<0.5 \mathrm{ng} / \mathrm{ml})$. The results of the tests for malaria, chikungunya, hantavirus and dengue were negative in all patients. Nasopharyngeal swabs were tested using RT-PCR and found to be positive for novel influenza A/H1N1 in all cases. In cases 2, 3, 8-10 and 12-14 (57.1\%), the microbiology laboratory was able to confirm the strain as pandemic novel A/H1N1/pdm (2009) strain, but confirmatory evidence of the pdm strain was not available for the rest.

Following a dilated fundus evaluation, three patients $(21.4 \%)$ showed ocular lesions. These three patients included one male and two females, aged 36-54 years (mean 46.0 years cases 7, 8 and 9) who demonstrated a unilateral intraretinal hemorrhage. These three patients had platelet counts ranging from $173,000-258,000 /$ cu.mm and had no evidence of a bleeding diathesis. 


\begin{tabular}{|c|c|c|c|c|}
\hline Sr No & Age/Sex & Clinical Presentation & $\begin{array}{l}\text { Anterior Segment } \\
\text { Findings }\end{array}$ & Posterior Segment Findings \\
\hline 1 & $54 / \mathrm{M}$ & Fever with ARDS & Normal & Normal \\
\hline 2 & $48 / \mathrm{M}$ & Fever with ARDS & Normal & Normal \\
\hline 3 & $75 / F$ & Fever & Normal & Normal \\
\hline 4 & $48 / \mathrm{M}$ & Fever/Pneumonia & Normal & Normal \\
\hline 5 & $74 / F$ & Fever/Pneumonia & Normal & Normal \\
\hline 6 & $57 / \mathrm{M}$ & Fever & Normal & Normal \\
\hline 7 & $54 / \mathrm{M}$ & Fever & Normal & 1/3 DD sized macular hemorrhage \\
\hline 8 & $48 / F$ & Fever with ARDS & Normal & $\begin{array}{l}\text { Disc hemorrhage with a } 4 D D \text { sized } \\
\text { area of macular retinal ischemia }\end{array}$ \\
\hline 9 & $36 / F$ & Fever with ARDS & Normal & $\begin{array}{l}\text { 4DD sized disc/peripapillary } \\
\text { hemorrhage }\end{array}$ \\
\hline 10 & $40 / \mathrm{M}$ & Fever & Normal & Normal \\
\hline 11 & $50 / \mathrm{M}$ & Fever with ARDS & Normal & Normal \\
\hline 12 & $41 / F$ & Fever & Normal & Normal \\
\hline 13 & $54 / \mathrm{M}$ & Fever & Normal & Normal \\
\hline 14 & $78 / F$ & fever & Normal & Normal \\
\hline
\end{tabular}

M, male; F, female; DD, disc diameter; ARDS, adult respiratory distress syndrome.

One patient in this group (case 8) had a large disc hemorrhage and an area of retinal whitening consistent with arterial occlusion and retinal ischemia in the macular area. This patient was a 36-year-old female who rapidly deteriorated with the development of a right cerebral bleed and a right arm radial artery thrombosis that required surgical embolectomy.

The single patient (case 7) who opted for domiciliary care, underwent a detailed evaluation. This patient's vision was $6 / 6$, N6 bilaterally with a normal anterior segment examination on slit-lamp evaluation. Dilated fundus evaluation revealed a $1 / 3$-disc diameter (DD) sized retinal hemorrhage in the right eye (Figure 1) and was normal in the left.

\section{Discussion}

We observed ocular lesions in three patients in the form of intraretinal and disc hemorrhages. One patient had disc hemorrhages and macular ischemia, consistent with arterial occlusion/ retinal ischemia along with systemic thrombotic events in the form of a cerebral bleed and a radial arterial thrombus. In our patients, thrombocytopenia or a bleeding diathesis did not seem to be the mechanism of these bleeds, thus suggesting an alternate mechanism.

Several authors have postulated the virus has a direct cytopathic effect on retinal, neuronal and vascular tissue. Studies of lung tissue have shown similar cytopathic effects on bronchial and alveolar epithelial cells ${ }^{8}$, as well as intraluminal fibrin thrombi and partial loss of the endothelium in intrapulmonary blood vessels $^{9}$. We hypothesize that similar patterns of retinal intravascular events, possibly induced directly by the virus or mediated through an immune reaction, may be responsible for our findings.

Bunce et al. studied 119 patients with H1N1 infections and were able to identify seven patients with systemic thrombotic events $^{10}$. Among the likely prothrombotic mechanisms, they identified enhanced platelet activation or endothelial dysfunction, suggesting that the etiopathogenesis of the arterial thrombi may involve endovascular injury or endothelial dysfunction with the release of proinflammatory mediators.

Breker et al. reported a case of a 13-year-old girl with a H1N1 infection who developed bilateral retinal and lateral geniculate body infarction ${ }^{5}$. They noted an ischemic retinal whitening with inner retinal thickening and hyperreflectivity which they hypothesized was an immune mediated complication. Roesel et al. described a 11-year-old girl with a H1N1 infection, who developed vitritis with massive choroidal exudation which was subsequently confirmed on ultrasound and optical coherence tomography (OCT). Following steroid therapy, the effusion significantly improved ${ }^{6}$.

The weaknesses of our study include a referral bias towards critically ill patients and the fact that referral for ophthalmic evaluation was at the discretion of physicians. Hence, this data does not reflect an accurate prevalence of all admitted patients, with a likely skew to a higher frequency of ocular 


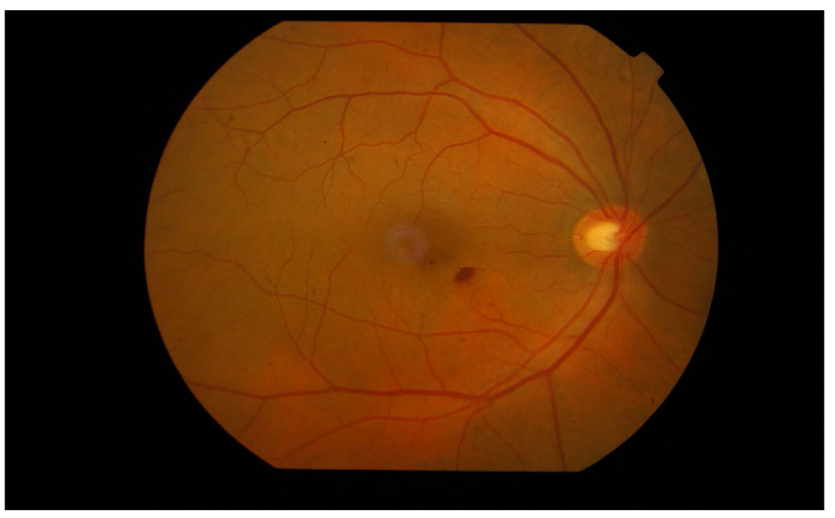

Figure 1. Fundus photo of the right eye of case 12 (a non-diabetic, non-hypertensive male) showing retinal haemorrhages in the macular area.

lesions. Virtually all of these patients were isolated or too ill to be moved for a more detailed evaluation including retinal angiography to assess the vascular integrity and patterns of blood flow.

This small study suggests that hitherto unreported ocular involvement in the form of hemorrhages/retinal ischemia may occur in these patients. Further data is needed to assess their significance, especially as prognostic indicators.

\section{Data availability}

Underlying data

Figshare: H1N1_figshare.xlsx. https://doi.org/10.6084/ m9.figshare. $8079743^{7}$
This project contains the following underlying data:

- H1N1_figshare.xlsx (spreadsheet containing results of tests for each patient)

Data are available under the terms of the Creative Commons Attribution 4.0 International license (CC-BY 4.0).

\section{Grant information}

The author(s) declared that no grants were involved in supporting this work.
1. National Centers for Disease Control: Seasonal Influenza (H1N1)- State/UT- wise, Year- wise number of cases and death from 2011 to 2018 (till $02^{\text {nd }}$ December, 2018). Accessed 13 December 2018.

Reference Source

2. Novel Swine-Origin Influenza A (H1N1) Virus Investigation Team, Dawood FS, Jain S, et al.: Emergence of a novel swine-origin influenza A (H1N1) virus in humans. N Engl J Med. 2009; 360(25): 2605-2615.

PubMed Abstract | Publisher Full Text

3. Prasad S, Indhu AJ, Margos RA, et al:: Clinical profile and outcome of H1N1 influenza patients in a tertiary care hospital in Kochi, Kerala. Indian J Respir Care. 2018; 7(2): 97-101. Publisher Full Text

4. Lee JH, Agarwal A, Mahendradas $\mathrm{P}$, et al: Viral posterior uveitis. Surv Ophthalmol. 2017; 62(4): 404-445.

PubMed Abstract | Publisher Full Text | Free Full Text

5. Breker DA, Stacey AW, Srinivasan A, et al.: Vision Loss Caused by Retinal and Lateral Geniculate Nucleus Infarction in H1N1 Influenza. J Neuroophthalmol.
2015; 35(3): 265-269

PubMed Abstract | Publisher Full Text

6. Roesel M, Heinz C, Heiligenhaus A: H1N1 and uveal effusion syndrome. Ophthalmology. 2010; 117(7): 1467-1467.e1.

PubMed Abstract | Publisher Full Text

7. Mehta S: H1N1_figshare.xlsx. 2019.

http://www.doi.org/10.6084/m9.figshare.8079743.v2

8. Mauad T, Hajiar LA, Callegari GD, et al.: Lung pathology in fatal novel human influenza A (H1N1) infection. Am J Respir Crit Care Med. 2010; 181(1): 72-9. PubMed Abstract | Publisher Full Text

9. Soto-Abraham MV, Soriano-Rosas J, Díaz-Quiñónez A, et al:: Pathological changes associated with the $2009 \mathrm{H} 1 \mathrm{~N} 1$ virus. N Engl J Med. 2009; 361(20): 2001-3.

PubMed Abstract | Publisher Full Text

10. Bunce PE, High SM, Nadjafi M, et al:: Pandemic H1N1 influenza infection and vascular thrombosis. Clin Infect Dis. 2011; 52(2): e14-7.

PubMed Abstract | Publisher Full Text 


\section{Open Peer Review}

\section{Current Peer Review Status: $\mathrm{X}$ ?}

\section{Version 1}

Reviewer Report 23 September 2019

https://doi.org/10.5256/f1000research.20748.r53508

(C) 2019 Esen F. This is an open access peer review report distributed under the terms of the Creative Commons Attribution License, which permits unrestricted use, distribution, and reproduction in any medium, provided the original work is properly cited.

\section{Fehim Esen}

Department of Ophthalmology, Istanbul Medeniyet University School of Medicine, Istanbul, Turkey

The authors describe ocular findings associated with H1N1 infection. There are 2 cases with asymptomatic retinal hemorrhages and 1 patient with retinal artery occlusion. This report of retinal involvement with $\mathrm{H} 1 \mathrm{~N} 1$ is new and interesting. The authors also ruled out the possibility of bleeding diathesis in these patients, supporting the possibility these findings are associated directly with $\mathrm{H} 1 \mathrm{~N} 1$ pathogenesis rather then a result of secondary systemic hematologic changes due to infections in general.

There are some issues related with the manuscript:

1. The authors mention that they have collected the patients over 9 years in the abstract. In the methods section, they mention that records of patients between 2015 and 2018 were examined. The dates don't match.

2. The authors report that pre-existing type 2 diabetes in 3 patients among $14 \mathrm{H} 1 \mathrm{~N} 1$ patients. However, it is unclear whether the cases that developed retinal lesions had diabetes or hypertension.

3. The authors mention that there were 12,942 infections of H1N1 in India last year, but they have only 14 cases from 3 years. A multicenter study with more cases would better describe this disease picture. This can be at least mentioned in the discussion.

Is the work clearly and accurately presented and does it cite the current literature? Yes

Is the study design appropriate and is the work technically sound? Yes

Are sufficient details of methods and analysis provided to allow replication by others? Partly 
If applicable, is the statistical analysis and its interpretation appropriate?

Not applicable

Are all the source data underlying the results available to ensure full reproducibility?

Partly

Are the conclusions drawn adequately supported by the results?

Partly

Competing Interests: No competing interests were disclosed.

Reviewer Expertise: Ocular inflammation, uveitis

I confirm that I have read this submission and believe that I have an appropriate level of expertise to confirm that it is of an acceptable scientific standard, however I have significant reservations, as outlined above.

Reviewer Report 03 June 2019

https://doi.org/10.5256/f1000research.20748.r49095

(c) 2019 Bansal R. This is an open access peer review report distributed under the terms of the Creative Commons Attribution License, which permits unrestricted use, distribution, and reproduction in any medium, provided the original work is properly cited.

\section{Reema Bansal}

Advanced Eye centre, Post Graduate Institute of Medical Education and Research (PGIMER), Chandigarh, Haryana, Punjab, India

In the abstract, the authors state 'over a period of nine years', whereas in the text, the study period mentioned is 2015-2018. Please clarify this.

As rightly said in the manuscript, the ocular involvement in $\mathrm{H} 1 \mathrm{~N} 1$ is very rare. However, the authors have missed discussing the following references, relevant to the disease:

1. Knapp A. Optic neuritis after influenza, with changes in the spinal fluid. Arch Ophthalmol. 1916;45:247-249. ${ }^{1}$

2. Mathur SP. Macular lesion after influenza. Br J Ophthalmol. 1958;42:702. ${ }^{2}$

3. Lai CC, Chang YS, Li ML, Chang CM, Huang FC, Tseng SH. Acute anterior uveitis and optic neuritis as ocular complications of influenza A infection in an 11-year-old boy.J Pediatr Ophthalmol Strabismus2011 Jul 6.48 Online:e30-3. doi: 10.3928/01913913-20110628-03. ${ }^{3}$

4. Rifkin L, Schaal S. H1N1-associated acute retinitis. Ocul Immunol Inflamm 2012;20:230-232. ${ }^{4}$

The manuscript largely discusses the systemic (rather than ocular) findings in details, both in Results as well as Discussion, leading to its suitability as an article for a Medicine journal, rather than Ophthalmology journal.

Almost all the references cited by the authors relate to systemic findings in $\mathrm{H} 1 \mathrm{~N} 1$.

Although the authors have discussed the limitations of their study, their findings are not robust enough to have a publication out of this study. None of their patients have been 
symptomatic for ocular examination. Moreover, the mere finding of an incidental retinal haemorrhage does not merit ophthalmic screening of these critically ill patients.

\section{References}

1. Knapp A: Optic neuritis after influenza, with changes in the spinal fluid. Arch Ophthalmol.1916;

45.

2. MATHUR SP: Macular lesion after influenza.Br J Ophthalmol. 1958; 42 (11): 702 PubMed Abstract I Publisher Full Text

3. Lai CC, Chang YS, Li ML, Chang CM, et al.: Acute anterior uveitis and optic neuritis as ocular complications of influenza A infection in an 11-year-old boy.J Pediatr Ophthalmol Strabismus. 2011; 48 Online: e30-3 PubMed Abstract | Publisher Full Text

4. Rifkin L, Schaal S: H1 N1 -associated Acute Retinitis. Ocular Immunology and Inflammation. 2012; 20 (3): 230-232 Publisher Full Text

Is the work clearly and accurately presented and does it cite the current literature? No

Is the study design appropriate and is the work technically sound? Partly

Are sufficient details of methods and analysis provided to allow replication by others? Yes

If applicable, is the statistical analysis and its interpretation appropriate? Yes

Are all the source data underlying the results available to ensure full reproducibility? Yes

Are the conclusions drawn adequately supported by the results? Partly

Competing Interests: No competing interests were disclosed.

Reviewer Expertise: Uveitis and Retina

I confirm that I have read this submission and believe that I have an appropriate level of expertise to state that I do not consider it to be of an acceptable scientific standard, for reasons outlined above. 
The benefits of publishing with F1000Research:

- Your article is published within days, with no editorial bias

- You can publish traditional articles, null/negative results, case reports, data notes and more

- The peer review process is transparent and collaborative

- Your article is indexed in PubMed after passing peer review

- Dedicated customer support at every stage

For pre-submission enquiries, contact research@f1000.com 